\title{
INCULCAR A SERIEDADE MEDIANTE A ALEGRIA: UM ESTUDO DAS COMEMORAÇÕES ESCOLARES NO CAMPO EDUCACIONAL (FINAIS DO SÉCULO XIX E INÍCIO DO XX)
}

\author{
Renata Marcílio Cândido* \\ lattes.cnpq.br/9931089607245261 \\ Denice Barbara Catani** \\ lattes.cnpq.br/3792758221330745
}

\begin{abstract}
Resumo: O artigo pretende analisar a construção do objeto festas no campo educacional, especialmente da história da educação, em sua multiplicidade de configurações, atentando não somente para a genealogia do evento no contexto escolar e a maneira pela qual o mesmo participou da organização de uma cultura própria da escola, mas também para as suas contribuições no processo de consolidação do campo em um contexto de organização do sistema público e estatal de ensino do Estado de São Paulo. A análise do evento beneficia-se de fontes como os periódicos educacionais da época (final do século XIX e início do XX) e da legislação de ensino. Opta-se por descrever aqui a articulação entre os festejos e os projetos formadores dominantes nas escolas, suas relações com outras áreas do saber e suas contribuições para o delineamento de questões de ensino.
\end{abstract}

Palavras-chave: Festas; Campo educacional; História da educação.

\section{INSTILLING SERIOUSNESS THROUGH JOY: AN ESSAY ABOUT SCHOOL CELEBRATIONS ON THE EDUCATIONAL FIELD (LATE NINETEENTH AND EARLY TWENTIETH-CENTURY)}

\begin{abstract}
This article intends to analyse the construction of the object school celebrations on the educational field, especially the educational history, regarding its multiplicity of configurations. Thus, not only is this work aimed to focus on the event genealogy in school context, and its participation in the organization of a school culture, but also on its contributions to the field consolidation process in an organizational context of the state public teaching system of São Paulo. The analysis of the event in the educational field benefit from studies sources such as late nineteenth-
\end{abstract}

\footnotetext{
* Doutora em Educação pela Universidade de São Paulo, USP (Brasil). Contato: remarcilio@gmail.com.

${ }^{* *}$ Doutora em Educação. Docente na Universidade de São Paulo, USP (Brasil). Contato: dbcat@usp.br.
} 
and early twentieth-century educational journals and education legislation as well. Seeing that, it is opted to describe the articulation between festivities and educational projects in particular which are dominant at schools, their relations with other knowledge areas, and also their contributions to framing teaching issues.

Keywords: Celebrations; Educational field; History education.

O cenário escolhido para análise dos eventos festivos realizados nas escolas é de grande movimentação, como um palco que deve mudar sua estrutura para novas ações. Assim como na festa, tudo que se realiza no campo educacional entre finais do século XIX e início do XX, precisa ser visto, celebrado e rapidamente conhecido pelo maior número de pessoas. A profusão das leis de ensino, a organização da carreira docente com a reabertura da Escola Normal de São Paulo com objetivo de formação do quadro docente específico para a carreira do magistério (TANURI, 1979), a construção de edifícios próprios para as escolas, a organização dos currículos e dos tempos escolares (GALLEGO, 2003), as publicações de periódicos especializados em questões educacionais e a criação da primeira associação de professores: Associação Beneficente do Professorado Público de São Paulo (1902) (CATANI, 1989) constituem alguns dos elementos que conformam e delineiam o campo educacional paulista naquele período e nas décadas subsequentes.

Como em um grande teatro, as comemorações escolares apresentam-se como forma de dar visibilidade a tudo o que estava sendo organizado e discutido no âmbito educacional. Por meio delas e das notícias sobre as mesmas é possível conhecer aspectos relevantes relacionados à imagem profissional docente e as representações de alunos, os conteúdos escolares aprendidos, as metodologias de ensino utilizadas, bem como os projetos dos governantes para o sistema de ensino que se constituía.

Tema de estudos recentes, a compreensão do evento beneficiar-seá, no caso desse artigo, da retomada, ainda que breve, de pesquisas acerca das festas realizadas em diferentes domínios como o sociológico, o 
histórico, o antropológico, buscando a multiplicidade de significados que tais eventos recebem dependendo do contexto histórico e social no qual se concretizam e das posições ocupadas pelos sujeitos que deles participam nestes espaços ${ }^{1}$. Em estudos realizados anteriormente percebe-se que, até num mesmo contexto histórico e educacional, as festividades assumem significados e funções distintas para os indivíduos que delas participam, evidenciando apropriações (CHARTIER, 1992) diversificadas do acontecimento. Já no âmbito escolar, mais do que momentos de divertimento, tais atividades assumem funções pedagógicas que extrapolam o contexto da sala de aula, invadindo outras esferas da vida social.

Considerando tais ideias, os questionamentos que norteiam a discussão neste texto almejam desvelar o que podemos saber sobre a cultura escolar (JULIA, 2001) de um determinado período histórico por meio das comemorações, especialmente as formas pelas quais elas contribuíram para a constituição do campo educacional destacando, na sua organização e realização, temas a serem debatidos, delimitando espaços privilegiados de discussões e as posições ocupadas pelos indivíduos naquele contexto educacional, em finais do século XIX e início do $\mathrm{XX}^{2}$. Tomam-se como fonte histórica os periódicos de ensino, veículos privilegiados em pesquisas de diferentes áreas que permitem identificar na multiplicidade do campo educativo as vozes, os projetos, os anseios e as realidades dos diversos atores envolvidos com as temáticas educacionais (CARVALHO, 1998; CATANI, 1989). Ao articular, em textos veiculados nesses meios, as teorias e as práticas educacionais, bem como as experiências individuais concretas dos educadores, compreendendo os desejos do futuro e a situação da época, pretende-se contribuir, conforme Nóvoa (1993), para a constituição de outra forma de investigar a cultura pedagógica.

\footnotetext{
${ }^{1}$ A seleção dos autores apresentadas na próxima parte deste texto pretende contemplar as formas distintas de tratar o tema comemorações em diferentes campos de saber, destacam-se estudiosos que de certo modo inauguram a discussão do tema festas ou de modos de tratá-las em suas respectivas áreas.

2 A discussão realizada subsidia-se na análise das notícias veiculadas nos principais periódicos de ensino circulantes no período em São Paulo, são eles: $A$ Eschola Publica (1893-1897), Revista de Ensino (1902-1919), Anuários de Ensino do Estado de São Paulo (1907-1926) e Revista Escolar (1925-1927).
} 
Tomamos o conceito campo educacional como um conjunto de espaços estruturados de posições (ou de postos) cujas propriedades dependem das posições nestes espaços podendo ser analisadas independentemente das características de seus ocupantes (BOURDIEU, 2003). Para que um campo funcione, é preciso que haja objetos de disputas e pessoas prontas para disputar o jogo, dotadas de habitus que impliquem no conhecimento e no reconhecimento das leis imanentes do jogo, dos objetos de disputa, etc. Desse modo, o sentido de campo educacional é o de pensar nos espaços: profissional, escolar e científico nos quais se cuida especialmente de fazer a educação, estudar seus processos e produzir conhecimentos a respeito.

\section{O caleidoscópio da festa e os modos de estudar o evento}

Estudos realizados em campos tais como a antropologia, a sociologia e a etnologia indicam a multiplicidade das dimensões do evento festivo e das formas de entendimento da questão. Entretanto, quando restringirmos a busca ao âmbito historiográfico (JANCSÓ; KANTOR, 2001), essas investigações tornam-se menos recorrentes, principalmente na história da educação, para as escolas públicas no período analisado neste artigo. Nas áreas indicadas, os trabalhos que se preocupam com o tema das comemorações podem ser divididos, de forma sumária, entre aqueles que tomam as festividades como aspecto da vida social dentre outros (OZOUF, 1976; DEL PRIORE, 2000), aqueles que as examinam em suas relações com outras dimensões da sociedade (DUVIGNOUD, 1983) e aqueles que discutem mais detidamente os rituais festivos em minúcias de significados (BRANDÃO, 1978; DAMATTA, 1990), e ainda outros que apresentam o funcionamento e as ressonâncias das festas nas sociedades e nos processos de formação dos sujeitos (BRANDÃO, 1978).

No âmbito dos estudos históricos, a inserção do tema festas só acontece devido à dupla instigação do folclore e da etnologia, segundo Ozouf (1976), considerando que a história tem tradicionalmente se pre- 
ocupado mais com os esforços e trabalhos dos homens do que com seus divertimentos. Temas como estes ganham visibilidade no campo histórico, a partir do marco teórico relacionado ao movimento dos Annales, caracterizado pela contestação dos métodos da história tradicional (BURKE, 1992), e no diálogo crescente da história com as outras disciplinas, contribuindo de maneira significativa para o aprimoramento das pesquisas, busca de novos métodos e objetos e redefinição de padrões profissionais de pesquisa.

Tais contribuições são retomadas em estudos históricoeducacionais, que em diálogo com outras áreas de estudos, propõe o abandono de hábitos antigos de pesquisa como a demarcação de territórios e novas possibilidades metodológicas (NÓVOA, 1993). Desse modo, a História da Educação beneficia-se com o extrapolar destes limites e o realizar-se na interação com outros domínios de saber, deixa-se de lado a "antiga" história baseada nos grandes nomes e feitos, na evolução do sistema educativo e das ideias pedagógicas, para se construir uma história mais relacionada ao cotidiano escolar, às práticas e às culturas escolares. É no âmbito desta reestruturação que o estudo acerca das festas escolares pode ser pensado e desenvolvido.

Investigações que tomam as festividades como um aspecto da vida social destacam, em diferentes contextos, a sua associação às instituições detentoras de poder político, como as Igrejas e o Estado. Neste caso, de acordo com Del Priori (2000), elas são apresentadas e podem ser concebidas como expressão teatral de uma organização social, de um fato político, religioso ou simbólico. Em outras palavras, a principal função das festas, era afirmar a perenidade das instituições de poder, que no período colonial brasileiro, buscaram normatizar essas manifestações e por meio delas a população brasileira.

Ainda assim, contra todas as regras que a Igreja e o Estado tentaram impor, as festividades esboçaram um trajeto feito de múltiplas funções: elas podiam servir como um "exutório para suportar as árduas condições de vida das classes subalternas na Colônia” (DEL PRIORI, 2000, p. 90); momento no qual os grupos sociais podiam exaltar suas posições e valores, seus privilégios e poderes, demonstrando publica- 
mente seu lugar na cidade e na sociedade e, aproveitando tais ocasiões para as revanches e reivindicações. Neste caso, depois de legitimadas socialmente, tais eventos parecem ganhar "vida própria" adquirindo outros sentidos e funções que não os pensados originalmente, indicando apropriações distintas das representações (CHARTIER, 1992) oficiais inicialmente pensadas.

As relações entre as comemorações e o poder político são destacadas por Mona Ozouf (1976) na sua análise acerca das comemorações relacionadas à Revolução Francesa. Naquele contexto, tais eventos almejaram anunciar um novo tempo histórico e garantir, na realidade, a esperança ou a ilusão de uma sociedade não repressiva, em que seriam abolidas as rupturas entre a vida cotidiana e as festividades. Apesar das suas diferenças, os eventos relacionados à revolução, de acordo com Ozouf (1976), apresentaram um mesmo cerimonial, inspirado na religião católica evidenciado na incorporação de hinos, passeatas e exortações com formatos semelhantes, mas com conteúdos distintos. Além disso, a semelhança existente entre as diversas festas da revolução buscou garantir a autenticidade das mesmas e a sua promessa de unanimidade. Existiu em comum a mesma vontade de substituir o culto católico por outro novo, capaz de oferecer aos indivíduos, de modo laico, a satisfação pretendida pelo ritual religioso. As cerimônias patrióticas apresentam-se, assim, como transposições das católicas (OZOUF, 1976) com propósitos semelhantes de congregação da população, mas com mensagens, símbolos e signos diferentes.

Assim como as posições sociais e os valores compartilhados, os elementos constitutivos das identidades de uma determinada sociedade também podem, segundo alguns autores (BRANDÃO, 1978; DAMATTA, 1990), ser estudados por meio das festas. Para Carlos Rodrigues Brandão (1978), os festejos religiosos e o folclore popular brasileiro permitem conhecer os modos simbolicamente mais profundos por meio dos quais as pessoas procuram estabelecer formas rituais de comunicação entre si e com os seus deuses e santos. "Está também presente aí uma das formas que a sociedade encontra para reescrever e traduzir, através da festa e do folguedo, o peso de sua ordem e também o de suas 
contradições” (BRANDÃO, 1978, p. 10). Neste caso, os fatos folclóricos não devem ser lidos em seus rituais sem perceber como os povos se organizam para cultuar os seus padroeiros e os sinais de sua própria identidade. Um dos aspectos mais curiosos no estudo de um fenômeno folclórico, segundo este autor é a tensão entre o seu núcleo de tradições e os segmentos de modificações; as tensões entre diversas categorias de agentes envolvidos e, finalmente, os significados da festa ou do folguedo, como uma situação cerimonial de reprodução simbólica de relações sociais.

A importância assinalada por Brandão (1978) acerca das comemorações sociais e religiosas são confirmadas por Roberto DaMatta (1990), que procura discutir em "Carnavais, malandros e heróis: para uma sociologia do dilema brasileiro" os caminhos que tornaram a sociedade brasileira diferente e única a partir da análise crítica do mundo cotidiano, ao lado do estudo das grandes formas de congraçamento, em especial o Carnaval. O autor apresenta uma concepção de solenidade como momento em que o tempo fica suspenso, o mundo pode ser reconstruído e a liberdade de expressão do homem pode ser vivida plenamente. O ritual constitui-se em um domínio privilegiado para manifestar aquilo que se deseja eterno, colocando-nos um problema de contrastes, "daí a necessidade absoluta de estudar o mundo social tomando como ponto de partida as relações entre seus momentos mais importantes: o mundo cotidiano e as festas; a rotina e o ritual; a vida e o sonho; a personagem real e o paradigma" (DAMATTA, 1990, p. 31).

Os trabalhos indicados até o momento denotam que as celebrações tiveram diferentes funções nos distintos espaços sociais e de investigação. Em uma mesma situação, um evento poderia ser percebido de forma distinta pelos participantes da comemoração e seus idealizadores que possuíam um propósito especificado por meio das normas, uma representação da festa ideal, que poderia vir a se implementar ou não. Já para a população que efetivamente concretizava o evento, ele poderia ter significados diferentes daqueles inicialmente propostos, a representação poderia ser única, mas as apropriações de cada evento eram distintas (CHARTIER, 1992). Além de uma tentativa de conformação de 
ideias e comportamentos, os eventos sociais também podem ser percebidos como espaços de lutas entre aqueles que os propunham e aqueles que os realizavam efetivamente.

As possibilidades de homogeneização de interesses e de conformação de papeis sociais presentes nas festividades podem ser ameaçadas por outra importante característica inerente as mesmas, que é o seu papel subversivo. Ao serem tomadas como momento de "subversão exaltante" por alguns autores, permitem a transformação do tempo ou até mesmo a sua supressão, a transformação da rotina e do espaço que, mesmo conhecido, passa a ser reapropriado: "ela é capaz de cortar uma sequência, quebrar o encadeamento dos acontecimentos que a ideologia histórica dominante nos apresenta como lógico e insuperável" (DUVIGNOUD, 1983, p. 24-25). Concebida nesta perspectiva, ela emerge como ato surpreendente e imprevisível, se declarando tanto durante as cerimônias rituais com as quais não se confunde, quanto ao longo de toda manifestação pública (idem, p. 31-32), ou nas palavras de Ozouf (1976), a circunstância decide a festa e a improvisação a completa. Ao mesmo tempo em que sistematiza a ordem da natureza, também possibilita a ruptura, a criação de algo novo, o improviso e a subversão.

A conformação e a subversão são elementos constitutivos das comemorações e não seria diferente no âmbito escolar. Os primeiros trabalhos produzidos pelos educadores da época (CINTRA, s/d; CARDIM, 1916; OLIVEIRA JR., s/d) acerca das comemorações apresentam de forma bastante prescritiva o objeto, indicando como elas deveriam acontecer, ou seja, as etapas de sua concretização, e como seus temas precisariam ser trabalhados antes e depois do evento, constituindo-se, dessa forma, material representativo do tipo de publicação, preponderantemente normativa, que circulou naquele período. A tônica que prevalece é a da conformação, assim como retrata Moysés Kuhlmann Jr. (2001) ao comparar os sistemas educacionais ocidentais por meio da solenidade Exposições Internacionais, realizadas em diferentes países do mundo no período entre 1862 e 1922.

Tais eventos constituíram-se oportunidades significativas para a proposição da educação como signo de modernidade, difundindo um 
conjunto de propostas nessa área, que abarcou desde materiais didáticos a métodos pedagógicos para diferentes instituições de ensino, da creche ao ensino superior. Já no Brasil, foi realizada uma solenidade semelhante, intitulada Exposição Pedagógica (1883), ocasião na qual as salas de aulas dos colégios particulares do país se encheram dos materiais de ensino considerados mais modernos e semelhantes aos que estavam sendo utilizados nos países europeus. A ideia era deixar patente a capacidade das escolas brasileiras acompanharem o desenvolvimento que ocorria no mundo europeu e norte-americano com relação ao ensino, tanto nos aspectos materiais como nas propostas metodológicas. A visibilidade permitida por estes eventos colaborou para uma hierarquia entre os países considerados mais e menos desenvolvidos e modernos.

Anos mais tarde, especificamente no contexto de implementação dos grupos escolares 3 em São Paulo, as solenidades ganham novos significados e passam a ser utilizadas em diferentes momentos da rotina escolar. Em “Templos de civilização”, Souza (1998), ao tratar no âmbito dos estudos de história da educação, do surgimento e consolidação desse tipo de estabelecimento de ensino nas primeiras décadas republicanas, descreve desde a escolha dos locais para a construção dos edifícios, passando pelos conteúdos e metodologia utilizados nessas instituições, identificando algumas comemorações, especialmente as levadas a efeito por ocasião dos exames, das formaturas e das datas cívicas, com atenção para as funções que elas assumiram naquele momento importante para a constituição de um sistema estatal de ensino (SOUZA, 1998).

Como parte de uma "arquitetura temporal" (GALLEGO, 2003), re-

3 Os grupos escolares paulistas (escolas graduadas cujo método de ensino é o simultâneo), criados em 1893, marcaram a organização dos sistemas públicos e estatais de ensino, especialmente por estabelecerem mudanças importantes na organização administrativa e pedagógica da escola primária, dentre estas a organização das festas. Apesar dos grupos terem assumido um caráter modelar, deve-se considerar a diversidade dos estabelecimentos de ensino primário existentes, pelo menos até 1930: escolas-modelo (criadas pela reforma de 1890 para a realização da prática de ensino dos estudantes normalistas), escolas reunidas (cujo número de alunos não era suficiente para se formar um grupo escolar) e escolas isoladas (com um único professor e alunos de diferentes idades e níveis de ensino no mesmo espaço). Além dessas distinções, existem aquelas percebidas entre os estabelecimentos localizados na zona urbana e na zona rural (SOUZA, 1998; GALLEGO, 2003). 
presentada por aspectos do calendário escolar como data de matrícula, início e fim das aulas, períodos de exames, horários de entradas e de saídas, quadros de horários a serem seguidos na organização das atividades dos professores e alunos: a divisão da semana e do dia de aula, as matérias e o tempo a ser dedicado ao ensino de cada uma delas, a hierarquia entre estas, o tempo de descanso (dos alunos e dos professores), os feriados e festas são capazes de ordenar as atividades pedagógicas, expressando a importância da pontualidade, da ordem e da disciplina em dias regulares e em "dias em vermelho no calendário escolar".

Os avanços no campo educacional representados pela construção e inauguração dos prédios destinados especificamente às práticas de ensino ganham visibilidade mais prolongada com a celebração das ações e a publicação das notícias relacionadas à mesma na imprensa especializada. Celebrar a escola e dar ritmo ao cotidiano escolar são funções das festas que se associam a outras relacionadas à formação da identidade docente como mostra a análise das imagens e representações dos professores na história da profissão docente (VICENTINI, 2002).

Considerando esta multiplicidade de objetivos, propostas, representações, apropriações e significações Ozouf (1976) compara a festa a uma máquina, que pode ser montada e desmontada para diferentes fins, sendo que a transformação de seus objetivos e finalidades implica também uma modificação dos sentidos atribuídos aos eventos pelos seus idealizadores e pelos participantes. Os componentes desta máquina seriam aqueles capazes de fazer a festa inteligível e de exercer atração em diferentes contextos. Esse conjunto de elementos pode ser entendido como uma técnica festiva, um ritual que se repete por diferentes instituições sociais (Estado, Igreja, instituições de ensino).

No âmbito escolar, a apropriação das comemorações não se deu de forma homogênea e direta, sem contradições, mas carrega mudanças de sentidos. O mesmo maquinário utilizado em outras esferas sociais e para outros fins precisou se adaptar ao novo contexto de idealização e concretização, reestruturar suas engrenagens e técnicas que deveriam servir a partir daquele momento (final do século XIX) a um propósito eminentemente educativo. Caberia às comemorações, assim como a todas as ativi- 
dades realizadas no contexto escolar, uma função de ensino e de aprendizagem, além da divulgação de um saber característico da escola moderna, contribuindo para a organização do sistema escolar e do campo educativo.

\section{A constituição da festa no campo educativo: compondo as peças do maquinário}

As disputas no campo educacional e os modos de propor as festividades iniciam-se pela referência à discussão sobre as datas que deveriam figurar no calendário escolar. A implementação do novo regime político e a constituição de um sistema público e estatal de ensino constituem momento de transformação social, propício, segundo alguns dirigentes, para a redefinição de normas, valores e poderes. As lutas pelas posições nos campos passam pela definição de objetos que merecem ser reconhecidos e legitimados, e um dos objetos desta disputa era o calendário das escolas públicas paulistas com a definição do tempo de funcionamento, dos períodos, das interrupções, das datas comemorativas e dos heróis que mereciam ser lembrados. Heróis e grandes feitos foram criados e cultivados e passaram a integrar o campo educacional. Era necessário desencadear emoção, encontrar símbolos dos fatos que se desejava recordar e provocar sentimentos para que as crianças aderissem a eles com paixão. Era preciso fazer com que o povo amasse a pátria e seus heróis e comemorassem a era republicana: hinos, hasteamento da bandeira, pavilhão escolar, músicas cujas letras faziam menção à pátria constituíram atividades decisivas na construção da memória coletiva oficial.

O gradativo detalhamento do calendário (duração do ensino primário e períodos para matrícula, datas para o início e fim das aulas, férias) e, especialmente, a determinação dos dias de comemorações integraram ações para se constituir um sistema de ensino homogêneo, além de constituírem-se em uma das tentativas para controlar as atividades no momento de organização do sistema de ensino estatal. O ca- 
lendário informava aos alunos e aos professores as formas de trabalhar de modo a tornar a utilização do tempo a mais produtiva possível, sendo a produtividade representada por mais conteúdos ensinados e aprendidos no menor tempo possível pelo maior número de pessoas (GALLEGO, 2003). As festas pareceram preencher esse requisito a partir do momento em que propunham a todos os alunos, pais e professores o ensinamento dos conteúdos, bem como os comportamentos, normas, valores, reelaborados pelas instituições de ensino e relacionados às datas festivas, além de indicarem os avanços do governo no âmbito educacional e das crianças nas escolas.

Surgiu então, a feliz ideia das festas escolares no fim de cada a no letivo, pelas quais se pudessem tornar bem frisante o desenvolvimento admirável e real das crianças educadas nas primeiras escolas-modelos e grupos escolares criados. (Revista de Ensino, dezembro de 1908, p. 35).

Nem sempre o processo de escolha das datas comemorativas foi pacífico, e chegou até a constituir objeto de lutas no interior do campo político e educacional. Como máquinas poderosas e prontas para serem montadas e desmontadas, elas poderiam servir a diferentes propósitos (OZOUF, 1976). No período posterior à Proclamação da República brasileira ficou patente a luta pela escolha da ideologia representativa do novo regime, batalhas ideológicas que eram acompanhadas e compostas das não menos importantes batalhas de símbolos e alegorias representativos da imagem do novo regime (CARVALHO, 1990) e capazes de serem disseminados pelas festas cívicas.

A instituição dos festejos, de acordo com o Decreto $\mathrm{n}^{\mathrm{O}} 155^{-\mathrm{B}}$, de 14 de janeiro de 1890 , almejou representar o estabelecimento da fraternidade universal inerente a qualquer regime republicano, capaz de comemorar a continuidade e a solidariedade de todas as gerações humanas. Cada pátria deveria instituir tais datas segundo os laços que as prenderiam aos seus destinos e aos de todos os povos. Elas deveriam garantir não só a fraternidade dos indivíduos pertencentes a uma determinada nação, mas de todos os povos do mundo; talvez, por este motivo, a inserção de datas comemorativas de outros países no calendário republi- 
cano brasileiro não soasse tão estranho como consta no referido documento 4 . A proposta da invenção da tradição republicana destacou ainda o seu pertencimento a uma fraternidade que se desejou universal "com países e/ou momentos visualizados como representantes do lema: liberdade, igualdade e fraternidade" (OLIVEIRA, 1989, p. 185), cujas datas comemorativas foram divididas em duas categorias: aquelas que privilegiaram a fraternidade universal ( $1 .^{\circ}$ de janeiro e 14 de julho), e as que se referiam mais diretamente à fraternidade nacional (21 de abril; 03 de maio; 07 de setembro e 15 de novembro).

Os dias selecionados para figurarem no calendário republicano brasileiro mesclam eventos e referências nacionais importantes em diferentes momentos políticos. Foram elas: 21 de abril, consagrado à comemoração dos precursores da Independência do Brasil, personificado na figura de Tiradentes; 03 de maio, assim como em Portugal, consagrado à comemoração da descoberta do país; 13 de maio, consagrado à comemoração da fraternidade dos brasileiros; 14 de julho, consagrado à comemoração da República, da Liberdade e da Independência dos povos americanos; 07 de setembro, consagrado à comemoração da Independência do País; 15 de novembro, consagrado à comemoração da proclamação da República; e Festa da Bandeira, realizada no dia 19 de novembro. Acrescentou-se a essas datas, o dia 24 de fevereiro, quando se comemorou a promulgação da Constituição da República, festa nacional decretada pelo Congresso Nacional no ano de 1891.

Tais datas, ao contrário do que se supõe, não significavam, no contexto referido, momentos de ruptura no desenvolvimento das atividades escolares, como muitos poderiam imaginar, mas um tempo também de aprendizado dos conteúdos e valores legitimados socialmente. Elas davam continuidade e confirmavam tudo aquilo que era aprendido nos bancos escolares, pois a partir dos seus temas e rituais ensinavam o que deveria ser valorizado e de que forma. Elas representaram outro uso do tempo de aprendizagem, aprendia-se e ensinava-se em um mo-

\footnotetext{
4 As comemorações republicanas brasileiras almejaram assinalar a continuidade com o passado, ou com parte desse passado, muito mais do que iniciar ou retomar princípios revolucionários, como aconteceu no caso francês.
} 
mento de descontração e de alegria (CÂNDIDO, 2012).

As festividades que ganharam espaço no calendário das escolas primárias foram distintas e representaram funções, sentidos e modos de celebrar diferentes. Festejava-se para civilizar, divulgar, inaugurar e encerrar o ano letivo. Dentre tais celebrações ainda cabem outras distinções: as festas cívicas, as de inauguração dos grupos escolares e de encerramento do ano letivo quando se realizavam os exames e se entregavam prêmios aos melhores alunos, além das comemorações das aves e das árvores. Os tempos dos festejos não eram menos rígidos do que o tempo da escola, eles tinham hora de início, de fim, das homenagens, das apresentações dos alunos, dos discursos dos professores e autoridades, enfim, tudo era devidamente programado (GALLEGO, 2003).

As datas a serem comemoradas foram determinadas pelos calendários, mas as festas também seguiram uma programação previamente definida pelas escolas e pelos órgãos administrativos superiores, como a Diretoria de Instrução Pública. Esses programas enviados às instituições de ensino eram geralmente publicados na seção de "Notícias" dos periódicos educacionais, juntamente com outras informações sobre as comemorações. A inclusão dos festejos nas práticas escolares demandou dos professores, dos diretores, inspetores e também dos alunos a incorporação de outros conhecimentos relacionados não só ao conteúdo da nova prática, mas também às melhores formas de organizá-las. Às atividades docentes de preparação das aulas, desenvolvimento das mesmas, correção de provas, de cadernos, foram acrescidas outras como ornamentação das salas de aulas e da escola para o dia festivo, preparação dos alunos para a recitação de poesias, homenagens, ensaios para as apresentações ginásticas e de exercícios físicos, desfiles, passeatas, ensino de marchas e cantos (CÂNDIDO, 2007).

A análise dos programas, nos quais se propunha a organização dos dias "em vermelho" e das sugestões de atividades a serem realizadas nas comemorações, ambas publicadas em revistas especializadas, evidenciaram o caráter pedagógico das mesmas e a busca de legitimidade no campo educacional. As comemorações pretenderam ensinar às crianças 
e aos adultos presentes a representatividade de cada data, bem como os valores e virtudes associados ao novo regime político - a República, evidenciado, por exemplo, nas homenagens às pessoas ilustres que compareciam nestas ocasiões, nos conteúdos das poesias, hinos declamados pelos alunos, e na prática das marchas pela cidade e hasteamento do pavilhão pelos alunos. Os programas variavam de acordo com as possibilidades de cada instituição escolar e com a data a ser comemorada, bem como com o contexto no qual acontecia a comemoração. O trecho a seguir exemplifica o cuidado na previsão das etapas a serem cumpridas:

a) Onde houver comissões regionais de escoteiros às cinco horas e meia, alvorada e hasteamento da bandeira nacional no acampamento e nos edifícios públicos. Onde for possível, deverão os escoteiros acampar de véspera, para a realização desta solenidade; b) Às nove horas, festa escolar, que será iniciada com o juramento à bandeira feito por todos os alunos das escolas, obedecendo a uma fórmula que oportunamente, vos será enviada. Por ocasião dessa festa deverão ser cantados o Hino Nacional, o Hino da Independência, o da Proclamação da República e o da Bandeira, devendo a solenidade terminar com o hasteamento do pavilhão escolar paulista, cantando, então, todos os alunos o Hino do Pavilhão. O pavilhão escolar deverá ser hasteado no mesmo mastro em que estiver hasteada a Bandeira Nacional, ficando colocado logo abaixo desta; c) Às 18 horas dar-se-á a solenidade do arreamento das bandeiras. Nas escolas isoladas de localidades onde não seja possível a execução do programa com todas as partes acima, deverá, entretanto, ser realizada a festa escolar das nove horas. (Anuário de Ensino do Estado de São Paulo, 1922, p. 303).

As escolas-modelo do sistema público de ensino paulista eram chamadas a dar o exemplo, que deveria se estender aos grupos escolares e dos grupos para as escolas isoladas, de uma forma hierárquica e gradativa, evidenciando a hierarquia presente no campo educacional que então se estruturava. As comemorações cívicas eram organizadas da seguinte maneira: o professor reunia seus melhores alunos para decorar a sala, dando-lhe um aspecto festivo e preparava um programa a ser executado no dia festivo, este programa estava dividido em duas partes: a primeira era iniciada por uma explicação clara e precisa do professor sobre a data, seguindo-se a esta lição uma seção cívica com- 
posta de trechos alusivos, poesias, pequenos discursos, monólogos, diálogos, comédias, intercalando-se esses trabalhos de declamação com hinos e cantos patrióticos; a segunda parte era preenchida por um trabalho escrito, em papel próprio, tendo uma gravura que sintetizava a festa. Os alunos, conforme a classe que frequentavam, copiavam trechos, escreviam ditados, faziam composições livres sobre a data nacional (CARDIM, 1916, p. 5).

Com grande animação realizaram-se os festejos do encerramento do ano escolar nas Escolas Modelo e Jardim da Infância da Capital. Começaram no dia 25 de Novembro pelo Jardim da Infância. Encantadora foi essa festa e de saudosas recordações, principalmente para os pais que viram seus filhinhos apresentar em público o resultado de alguns meses de carinhoso cultivo. Depois de encerrados os trabalhos, com brinquedos, pequenas poesias escritas principalmente para o ato, cantos e marchas, foram as crianças conduzidas em bondes especiais ao jardim público, onde pelas professoras foi oferecido aos seus alunos um lunch de despedida. (A Eschola Publica, 15 de dezembro de 1896, p. 422-423).

A instituição das festas no contexto assinalado permite compreender em um primeiro momento a luta no campo educacional para a indicação dos dias a serem celebrados nos calendários escolares e suas relações com a consolidação da República brasileira. Os modos de celebrar, prescritos nos programas oficiais, indicam as posições ocupadas pelas diferentes instituições de ensino no âmbito educacional, para as escolas centrais e modelos, tais como os grupos escolares, eventos grandiosos e de grande divulgação, em escolas menores e afastadas, como as escolas isoladas, formas mais discretas e menos glamorosas de celebração, indicando assim, as posições ocupadas pelas instituições e indivíduos que delas participavam no campo educacional. As comemorações escolares marcam, desse modo, a hierarquia que perdurará durante um tempo entre as escolas do sistema de ensino paulista, assinalando qual espaço e legitimidade pertence a cada uma delas. 


\section{Do professor ideal e do aluno exemplar: os discursos comemorativos e a conformação das representações no campo educacional}

Assim como o calendário ao indicar as datas a serem comemoradas e as formas adequadas de realizá-las, os discursos proferidos pelos educadores e outras pessoas que ocupavam cargos de destaque na sociedade influenciaram a construção das maneiras de "ser e estar na profissão" docente. Estes discursos constituíram parte importante dos festejos, substituindo, não poucas vezes, as descrições dos mesmos nos periódicos. Percebeu-se que ao tratarem de temas não só relacionados à data festiva, mas também de questões educacionais mais amplas como, por exemplo, a função da educação, a "missão do educador", o aluno "ideal”, a crise moral que ameaçava a sociedade, estes textos almejaram forjar identidades docentes e construir modelos de vida escolar que ultrapassassem os muros das escolas e conformassem outros âmbitos da vida social. Estes saberes, veiculados nos discursos proferidos, ao contrário dos outros momentos, eram destinados principalmente aos adultos, pais e professores presentes em tais ocasiões, que podiam compreender de forma mais aprofundada as mensagens transmitidas (CÂNDIDO, 2012).

Relacionado ao fazer docente, os discursos retomados nos relatórios dos inspetores ou nos periódicos traziam referências às qualidades a serem observadas nas práticas dos professores (pontualidade, cumprimento das obrigações, respeito ao tempo destinado a cada atividade, disciplina, etc.) (Revista de Ensino, 1907)5. Ao utilizar de tal estratégia, o Estado recorreu a uma série de referências acerca do tipo de professor ideal, quer seja em relação as suas qualidades morais e sociais e sobre suas virtudes e capacidades, que deveriam ser postas a serviço do projeto de educação vislumbrado, fazendo das comemorações importantes momentos nos quais o Estado poderia disseminar seu ideal de

\footnotetext{
5 A referência ao periódico e não ao autor do texto se deve ao fato de vários escritos publicados neste periódico, bem como em outros do período, não deixarem identificados os nomes dos autores na publicação.
} 
cidadão para alunos, professores e população que assistiam tais solenidades.

Posto ao serviço da revolução republicana, em primeiro lugar, ou da própria República, em seguida, o exercício da profissão ficou desde então associado ao paradigma do professor missionário, capaz de sacrificar ou abandonar ambições pessoais legítimas, mantendo-se à margem de qualquer atividade reivindicativa, em troca de um destino profissional reputado transcendente. (FERNANDES, 1998, p. 12).

No discurso oficial, uma das tarefas primordiais na "missão do professor" era a formação do caráter dos educandos, entendida como formação moral do "bom cidadão" e da "boa mãe". Neste sentido, cabe retomarmos a alocução de José Feliciano de Oliveira (1903), exemplo da opinião dos educadores cujas palavras sobre esse tema foram registradas nos periódicos. Para aquele professor, o verdadeiro sentido da educação era justamente a formação dos cidadãos, sendo o civismo o mais alargado sentimento social, que formaria a "simpatia universal" e a união dos povos. "Ser um bom cidadão é a maneira mais decisiva de ser um bom homem, um homem social” (OLIVEIRA, 1903). Caberia aos educadores encaminhar metodicamente o espírito dos alunos, fortalecendo-lhes a vontade. "Enfim, antes de tudo, tratai de saber como se educa instruindo. Formai uma ideia segura do que seja a educação verdadeira e buscai sistematizar um conjunto de meios para realizá-la com a instrução" (OLIVEIRA, 1903).

Há um esforço notável para circunscrever de modo padronizado as práticas no interior das escolas haja vista a quantidade de prescrições voltadas aos professores. Todas essas recomendações apresentaram um modelo de professor e de profissão docente a ser perseguido. As preleções, ao serem pronunciadas em ocasiões especiais denotaram a importância de tais ensinamentos não só para os professores que deveriam praticá-los, mas também para os pais e sociedade em geral, que deveriam cobrá-los dos mestres de seus filhos. Por outro lado, o esforço para que o saber acerca da profissão explicitado nos discursos fosse incorporado nas práticas parece desconsiderar que os professores 
constroem, a partir do seu contexto de trabalho, formação e experiência anterior, o seu modo de organizar as aulas, de se movimentar na sala, de se dirigir aos alunos, de utilizar os meios pedagógicos mediante uma série de elementos, não só o discurso oficial (GALLEGO, 2003).

A presença das datas festivas nos calendários escolares e as orientações sobre a realização das mesmas enviadas em circulares pelas Diretorias de Ensino demandavam dos professores investimento no conhecimento destas novas práticas e nas formas de concretizá-las satisfatoriamente, ou seja, de acordo com o que era previsto nas regulamentações legais. Estas transformações ocorridas no âmbito do ensino interferiram na forma como os professores concebiam sua profissão, sua prática e os alunos, contribuindo para a modificação de suas identidades e as ideias sobre o fazer docente.

Os professores que, antes se detinham nas atividades inerentes à sala de aula, tiveram incorporadas às suas atribuições a responsabilidade pela preparação das festas, nas quais não só o seu desempenho era avaliado, mas dos seus alunos, do desenvolvimento do ensino e das escolas. Assim, entre os atributos da excelência docente no período contavam-se também as maneiras ideais de festejar, celebrar e comemorar. Um "bom" professor seria aquele capaz de cumprir todas as atividades previstas nos calendários e programas para os dias considerados "normais" de aula e as datas festivas e ainda resguardar a escola infantil contra a "epidemia da crise moral" que assolava a sociedade (Revista de Ensino, novembro de 1907).

Carlos A. Gomes Cardim, então inspetor de ensino, afirmou que em todos os atos dos alunos percebia-se sempre o reflexo do mestre, porque este "pela sugestão, incute-lhe todas as qualidades que possui" (Revista de Ensino, março de 1908, p. 31). Além de ser um exemplo de boa conduta, um bom professor, segundo Dino Bueno, era aquele que praticava sua "missão" com amor, já que este era o princípio criador de todas as coisas, inclusive de homens para a sociedade (Revista de Ensino, março de 1906, p. 807). Por outro lado, um mau mestre representava um "perigo social de consequências desastrosíssimas", influenciando seus alunos que, em seu convívio imediato, tornavam- 
se verdadeiros "veículos de propaganda" das qualidades "deploráveis do seu mau guia” (idem, p. 808). Desse modo, segundo o autor, era possível a partir da observação do comportamento das crianças perceber as qualidades e defeitos do seu mestre.

A escola se constituía como o local privilegiado para a formação dos futuros cidadãos e as comemorações contribuíram para tal intento já que foram consideradas ocasiões nas quais a sociedade poderia comprovar os benefícios das instituições de ensino como o melhor lugar para a educação dos alunos, considerados o futuro e a garantia do progresso social do país. O objetivo da escola não deveria se resumir ao desenvolvimento intelectual dos alunos, mas também contribuir para o seu desenvolvimento físico e moral. As festas constituíam-se em oportunidades para a comprovação dos avanços alcançados pela escola no desenvolvimento das crianças.

\section{Para finalizar e recomeçar...}

Se as festas foram importantes em um primeiro momento para a consolidação dos ideais republicanos e para dar visibilidade à escola pública, em um momento posterior esse objetivo foi contestado e elas continuaram acontecendo, mas com outros sentidos e propósitos que não os mobilizados inicialmente. Pode-se atribuir essas alterações no papel das festividades à própria assimilação dessas à cultura escolar. Quando as escolas-modelo e os grupos escolares foram criados, muitas foram às mudanças incorporadas por professores, alunos e também pelos pais. Novos temas e questões para debate se tornaram urgentes ao campo educacional. Nesse sentido, as comemorações consistiram em um dos vários aspectos introduzidos e que gradativamente entranharam-se nas representações sociais do que compõe a cultura escolar (JULIA, 2001).

A comemoração como observatório do campo educacional permite conhecer o conjunto de forças por vezes congruentes, por vezes antagônicas, responsáveis pela permanência das mesmas na cultura escolar e pela 
reinvenção constante dos seus usos e funções, de acordo com as urgências dos contextos sociais e históricos vivenciados. No momento de organização do campo educacional paulista (final do século XIX e início do $\mathrm{XX}$ ) elas permitem conhecer as questões educacionais prementes, bem como os espaços legítimos de discussão (instituições, periódicos...) e os indivíduos autorizados ao mesmo. Na aparência de um ato alegre e descontraído, concretizavam-se questões bastante sérias nos momentos festivos discutidos neste artigo, como a forma ideal de organizar os sistemas públicos de ensino e nestes os espaços ocupados por cada tipo de escola, suas hierarquias e espaços de ação, bem como as características associadas às posições dos professores nesse campo, suas principais características profissionais e pessoais, indicando que festejar é algo sério.

\section{Referências}

AZANHA, J. M. P. Cultura escolar brasileira: um programa de pesquisas. Revista USP, p. 65-69, 1990-1991.

BERGAMASCO, C. M. S. O fio de Ariadine: a religiosidade nas festas comemorativas escolares. Dissertação de mestrado (Educação). Universidade Estadual Paulista, Presidente Prudente, 2009.

BRANDÃO, C. R. O Divino, O Santo e A Senhora. Rio de Janeiro: Campanha de Defesa do Folclore Brasileiro, 1978.

BOURDIEU, P. Questões de Sociologia. Lisboa: Fim de Século, Edições, Sociedade Unipessoal, 2003.

BURKE, P. A Escola dos Annales (1929-1989): a Revolução Francesa da Historiografia. São Paulo: UNESP, 1991.

- Abertura: a nova História, seu passado e seu futuro. In: BURKE, P. (org.). A escrita da História: novas perspectivas. São Paulo: UNESP, 1992, p.7-37.

CÂNDIDO, R. M. A máquina de festejar: os usos e funções das festas escolares no Brasil e Portugal (1870-1960). Tese de doutorado (Educação). Universidade de São Paulo, São Paulo, 2012.

- Culturas da escola: as festas nas escolas públicas paulistas 
(1890-1930). Dissertação de mestrado (Educação). Universidade de São Paulo, São Paulo, 2007.

CARDIM, C. A. G. As comemorações cívicas e As Festas Escolares. São Paulo: Augusto Siqueira \& C., 1916.

CARVAlHO, J. M. A formação das almas. São Paulo: Companhia das Letras, 1990.

CARVALHO, M. M. C. A escola e a República. São Paulo: Brasiliense, 1989. . Por uma história cultural dos saberes pedagógicos. In: SOUZA, C. P.; CATANI, D. B. (org.). Práticas educativas, culturas escolares, profissão docente. São Paulo: Escrituras, 1998, p. 31-40.

CATANI, D. B. Educadores à meia luz: um estudo sobre a Revista de Ensino da Associação Beneficente do Professorado Público de São Paulo. Tese de doutorado (Educação), Universidade de São Paulo, São Paulo, 1989.

CHARTIER, R. A História Cultural: entre práticas e representações. Lisboa: Difel, 1990.

CINTRA, A. Alma Brasileira. São Paulo: Cia. Melhoramentos de São Paulo (Weiszflog Irmãos Incorporado), $5^{\mathrm{a}}$ ed., s/d.

DAMATTA, R. Carnavais, malandros e heróis. Para uma sociologia do dilema brasileiro. 5. ${ }^{\text {a }}$ ed. Rio de Janeiro: Guanabara, 1990.

DUVIGNOUD, J. Festas e civilizações. Rio de Janeiro: Editora Tempo Brasileiro, 1983.

FERNANDES, R. A história da educação no Brasil e em Portugal - caminhos cruzados. Revista Brasileira de Educação, n. 7, p. 1-14, 1998.

FOUCAULT, M. A arqueologia do saber. Rio de Janeiro: Forense Universitária, $7 .^{\mathrm{a}}$ ed., 2004.

FRANKFURT, S. H. As práticas das festas escolares na Escola Normal de Pirassununga (1931-1950). Dissertação de mestrado (Educação). Pontifícia Universidade Católica de São Paulo, São Paulo, 2007.

GALLEGO, R. C. Uso(s) do tempo: a organização das atividades de alunos e professores nas escolas primárias paulistas (1890-1929). Dissertação de mestrado (Educação). Universidade de São Paulo, São Paulo, 2003.

JANCSÓ, I.; KANTOR, I. Festa: cultura e sociabilidade na América Portuguesa. Seminário Internacional Festa: cultura e sociabilidade na América Portuguesa. São Paulo, 1999.

JULIA, D. A cultura escolar como objeto histórico. Revista Brasileira de História da Educação, n. 1, p. 9-43, 2001.

KUHLMANN JR., M. As grandes festas didáticas: a educação brasileira e as exposições internacionais (1862-1922). Bragança Paulista: Editora da Universidade São Francisco, 2001. LAWN, M. Os professores e a fabricação de identidades. In: NÓVOA, 
A., SCHRIEWER, J. A difusão mundial da escola: alunos, professores, currículo, pedagogia. Lisboa: Educa, 2000.

MAIA, S. A. Grupo escolar Duque de Caxias festas escolares: uma celebração de múltiplos significados (1949-1962). Dissertação de mestrado (Educação). Universidade Federal do Rio Grande do Norte, Natal, 2012.

MELO, S. M. B. A construção da memória cívica: as festas escolares espetáculos de civilidade no Piauí (1930-1945). Tese de doutorado (Educação), Fortaleza, 2009.

NÓVOA, A. Perspectivas de renovação da História da Educação em Portugal. In: NÓVOA, A.; BERRIO, J. (org.). A História da Educação em Espanha e Portugal. Lisboa: Sociedade Portuguesa de Ciências da Educação, 1993, p. 11-20.

OLIVEIRA, L. L. As festas que a República manda guardar. Estudos Históricos. Rio de Janeiro, v. 2, n. 4, p. 172-189, 1989.

OLIVEIRA, M. R. Sentidos e significações das festas escolares: implicações na construção do conhecimento social e da noção de cidadania. Ribeirão Preto: Centro Universitário Moura Lacerda, 2010.

OZOUF, M. A festa: sob a Revolução Francesa. In: LE GOFF, J.; NORA, P. História: novos objetos. Rio de Janeiro: Francisco Alves, 1976, p. 216-232.

PRIORE, M. Festas e utopias no Brasil Colonial. São Paulo: Brasiliense, 2000.

SILVA, M. C. C. B. As festas escolares no Brasil: uma análise a partir da literatura sobre a temática e à luz da teoria crítica. Dissertação de mestrado (Educação), Universidade Estadual Paulista, Marília, 2015.

SOUZA, M. P. "Nossa pátria, nossa bandeira, nosso chefe": as comemorações cívicas nas escolas de Santos durante o Estado Novo (1937). Dissertação de mestrado (Educação). Universidade Católica de Santos, 2013.

SOUZA, R. F. Templos de civilização: a implantação da Escola Primária Graduada no estado de São Paulo, 1890-1910. São Paulo: UNESP, 1999.

TANURI, L. O ensino normal no estado de São Paulo: 189o-1930. São Paulo: FEUSP, 1979.

VICENTINI, P. P. Imagens e representações de professores na história da profissão docente no Brasil (1933-1963). Tese de doutorado (Educação) Universidade de São Paulo, São Paulo, 2002. 